\title{
Cytotoxic Potential, Metabolic Profiling, and Liposomes of Coscinoderma sp. Crude Extract Supported by in silico Analysis
}

\begin{abstract}
Arafa Musa, (D) ${ }^{1,2}$ Abeer $\mathrm{H}$ Elmaidomy, (DD ${ }^{3}$ Ahmed M Sayed, ${ }^{4}$ Sami I Alzarea, ${ }^{5}$ Mohammad M Al-Sanea, $\mathbb{D}^{6}$ Ehab $M$ Mostafa, (D) ${ }^{1,2}$ Omina Magdy Hendawy, 5,7 Mohamed A Abdelgawad, (D) ${ }^{6}$ Khayrya A Youssif, ${ }^{8}$ Hesham Refaat, (ID) Eman Alaaeldin, ${ }^{10,11}$ Usama Ramadan Abdelmohsen ${ }^{12,13}$

'Department of Pharmacognosy, College of Pharmacy, Jouf University, Sakaka, 7234I, Saudi Arabia; ${ }^{2}$ Department of Pharmacognosy, Faculty of Pharmacy, Al-Azhar University, Cairo, II37I, Egypt; ${ }^{3}$ Department of Pharmacognosy, Faculty of Pharmacy, Beni-Suef University, Beni-Suef, 625II, Egypt; ${ }^{4}$ Department of Pharmacognosy, Faculty of Pharmacy, Nahda University, Beni-Suef, 62513, Egypt; ${ }^{5}$ Department of Pharmacology, College of Pharmacy, Jouf University, Sakaka, Aljouf, 7234I, Saudi Arabia; ${ }^{6}$ Pharmaceutical Chemistry Department, College of Pharmacy, Jouf University, Sakaka, Aljouf, 7234I, Saudi Arabia; ${ }^{7}$ Department of Clinical Pharmacology, Faculty of Medicine, Beni-Suef University, BeniSuef, 625I3, Egypt; ${ }^{8}$ Department of Pharmacognosy, Faculty of Pharmacy, Modern University for Technology and Information, Cairo, Egypt; ${ }^{9}$ Department of Pharmaceutics, Faculty of Pharmacy, Deraya University, 7 Universities Zone, New Minia, 6IIII, Egypt; ${ }^{10}$ Department of Pharmaceutics, Faculty of Pharmacy, Minia University, Minia, 61519, Egypt; "'Department of Clinical Pharmacy, Faculty of Pharmacy, Deraya University, 7 Universities Zone, New Minia, 6I I I I, Egypt; ${ }^{12}$ Department of Pharmacognosy, Faculty of Pharmacy, Minia University, Minia, 61519, Egypt; ${ }^{13}$ Department of Pharmacognosy, Faculty of Pharmacy, Deraya University, 7 Universities Zone, New Minia, 6IIII, Egypt
\end{abstract}

Correspondence: Eman Alaaeldin Department of Pharmaceutics, Faculty of Pharmacy, Minia University, Minia, 61519, Egypt

Email Eman_alaa_eldin@yahoo.com
Introduction: Sponge-Coscinoderma sp. (Family: Spongiidae) is a coastal sponge that possesses a broad variety of natural-products. However, the exact chemical constituents and cytotoxic activity of the extract are still undefinable.

Methodology: In the present study, the metabolomic profiling of Coscinoderma sp. dereplicated 20 compounds, utilizing liquid chromatography coupled with high-resolution mass spectrometry (LC-HRESIMS). Coscinoderma-derived crude extract, before and after encapsulation within nanosized liposomes, was in vitro screened against hepatic, breast, and colorectal carcinoma human cell lines (HepG2, MCF-7, and Caco-2, respectively).

Results: The identified metabolites were fit to diverse chemical classes, covering diterpenes, an indole alkaloid, sesterterpenoid, sterol, and methylherbipoline salt. Comprehensive in silico experiments predicted several compounds in the sponge-derived extract (eg, compounds 1-15) to have an anticancer potential via targeting multiple targets. The crude extract showed moderate antiproliferative activities towards studied cell lines with $\mathrm{IC}_{50}$ values range from 10.7 to $12.4 \mu \mathrm{g} / \mathrm{mL}$. The formulated extract-containing liposomes (size $141 \pm 12.3 \mathrm{~nm}$, PDI 0.222 , zeta potential $20.8 \pm 2.3$ ), significantly enhanced the in vitro anticancer activity of the entrapped extract ( $\mathrm{IC}_{50}$ values ranged from 1.7 to $4.1 \mu \mathrm{g} / \mathrm{mL}$ ).

Discussion: Encapsulation of both the hydrophilic and the lipophilic components of the extract within the lipid-based nanovesicles enhanced the cellular uptake and accessibility of the entrapped cargo. This study introduces liposomal nano-vesicles as a promising approach to improve the therapeutic potential of sponge-derived extracts.

Keywords: Coscinoderma, sponge, LC-HRESIMS, metabolic profiling, antiproliferative, liposomes

\section{Introduction}

The taxonomic biodiversity of coastal living forms had passed up to $30 \times 10^{6}$ species involving greater than $70 \%$ of the earth's surface. However, the total of biologically effective compounds from this enormous origin was restricted to a few thousand. ${ }^{1}$ Therefore, it was obvious to predict that marine organisms expressed an exceedingly valuable source of novel bioactive materials that can drive the outcome of different drugs. ${ }^{2}$ Natural products from marine origin as sponges and echinoderms had been explored broadly for their biological activities. ${ }^{3-5}$

The spongeCoscinoderma sp. (Family: Spongiidae), fitted to an arrangement of coastal sponges that had a broad variety of natural products, covering diterpenes, sesquiterpene hydroquinones, long-chain aliphatic and acetylenic compounds, 
furanic and scalarane sesterterpenes, bromotyrosine alkaloids, hepta- and octaprenylhydroquinones, suvanine analogs, and farnesyl quinols, which reported to have antitumor, antimalarial, antibacterial, antifungal, and protein tyrosine phosphatase-1B (PTP1B) inhibitoryactivities. ${ }^{6}$ Despite that Cosinoderma has shown a wide range of biological activities, its chemical constituents are still elusive. Consequently, we selected this sponge in the present to shed some light on its chemical makeup and to investigate its potential as anticancer agent depending on a comprehensive in silico predictive study and a subsequent in vitro validation.

Liposomes are lipid-based bilayer nanovesicles that are capable of entrapment of both hydrophilic and lipophilic drugs either inside its core or within the phospholipid bilayer, respectively. ${ }^{7}$ Many studies have reported the impact of formulating natural products within liposomal nano-vesicles in the entrapment of both hydrophilic and lipophilic constituents, ${ }^{8}$ improvement of stability of entrapped cargo, ${ }^{9}$ improvement of cellular uptake of that natural components ${ }^{10}$ and targeted delivery to the definite site of action. ${ }^{11-13}$ Liposomes have the advantages of being biocompatible, nonimmunogenic, and flexible dosage form that achieves the controlled delivery of the entrapped active constituents. ${ }^{14,15}$ Several techniques have been adopted for the formation of liposomes including thin-film hydration method, ${ }^{16}$ spraying technique ${ }^{8}$ and ethanol injection method. ${ }^{17}$ The ethanol injection method is a favorable technique because it is simple and enables the nonmixing of the organic phase with the aqueous one producing homogenous nanosized vesicles. ${ }^{18}$

Despite the wide range of therapeutic benefits of Coscinoderma sp., its low bioavailability, and leakage of suitable formulation retard the clinical application of such promising marine product. Formulating a convenient dosage form that can guarantee the entire inclusion, enhanced stability, and the cellular delivery of its physicochemically diverse components was a necessity. Consequently, the main purposes of the present investigation are to investigate the chemical profile of the Cosinoderma extract, predict the most probable bioactivity of this extract depending on a comprehensive in silico study of its main components, and test this predicted bioactivity in vitro, with study if the biological activity was enhanced upon entrapment of the extract into nanoformulation.

\section{Materials and Methods}

\section{Sponge Material}

Coscinoderma sp. sponge was collected from Ahia Reefs. Coscinoderma sp. was kindly identified by El-Sayed Abed El-Aziz (Department of Invertebrates Lab., National Institute of Oceanography and Fisheries, Red Sea Branch, 84511 Hurghada, Egypt). A voucher specimen (2020-BuPD 76) was deposited at the Department of Pharmacognosy, Faculty of Pharmacy, Beni-Suef University, Egypt.

\section{Chemicals and Reagents}

Chemicals and reagents used in this study were described in detail on Supplementary Material and Methods Chemicals and reagents.

\section{Metabolomic Analysis Procedure}

Freeze-dry sponge material $(8 \mathrm{~g})$ was extracted with methanol methylene chloride (1:1). The crude extract, developed at $1 \mathrm{mg} / \mathrm{mL}$ for mass spectrometry analysis. The recovered ethanolic extract was exposed to metabolic analysis using LC-HRESIMS. ${ }^{19-21}$ The details for the LC-HRESIMS method are described on Supplementary Material and

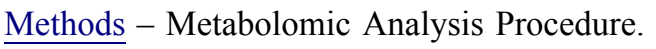

\section{Preparation of Coscinoderma sp.-Containing Liposomes}

Liposomes were developed by the simple ethanol injection method. ${ }^{18}$ The details for the utilized method are described in Supplementary Material and Methods - Preparation of Coscinoderma sp.-containing liposomes.

\section{Characterization of Coscinoderma sp.-Containing Liposomes}

Size and polydispersity index of Coscinoderma sp. containing liposomes were assigned with Zetasizer Nano ZSP (Malvern Instruments, Malvern, -UK). The details for the utilized method described in Supplementary Material and Methods - Characterization of Coscinoderma sp.containing liposomes.

\section{Transmission Electron Microscopy (TEM)}

Prepared liposomes of Coscinoderma sp. were imaged using (JEM-1400, Jeol, Tokyo, Japan) equipped at $80 \mathrm{kV}$. The liposomal suspension was imaged on a carbon-coated copper grid which was left for 10 minutes at $25^{\circ} \mathrm{C}$ before examination. ${ }^{17}$ 


\section{FTIR and TGA of Coscinoderma sp.-Containing Liposomes}

The effect of temperature on the weight of empty liposomes and Coscinoderma extract either free or encapsulated within the prepared liposomes was studied using Thermogravimetric Analysis (TGA). Samples were dried and 20 dried samples were heated from $30^{\circ} \mathrm{C}$ to $450^{\circ} \mathrm{C}$ in a platinum pan (heat flow rate of $20^{\circ} \mathrm{C} / \mathrm{min}$ and nitrogen flow rate $20 \mathrm{~mL} / \mathrm{min}$ ). To gain more insight into the probable interaction between lipoid S75, cholesterol, and Coscinoderma extract, Fourier-transform infrared (FT-IR) measurements were carried out for the Coscinoderma extract, blank liposomes, and Coscinoderma liposomes over the wavenumber range 4000 to $400 \mathrm{~cm}$ (Nicolet IS 10 FTIR spectrometer, US) after the dispersion of samples in $\mathrm{KBr}$ discs.

\section{Ethical Statement}

This study was developed under the guidelines of the United Kingdom Coordinating Committee on Cancer Research (UKCCCR) that addressed the Use of cell lines in cancer research.

\section{Cell Culture Conditions}

The cancer cell lines HepG2, MCF7, and Caco-2 culture condition described in Supplementary Material and

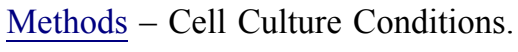

\section{Antiproliferative Assay}

The antiproliferative activity of Coscinoderma sp.containing liposomes and their corresponding empty liposomes were described in detail in Supplementary Material and Methods - Antiproliferative assay.

\section{In silico Biological Activity Predictions}

PASS $^{22}$ was employed for the prediction of the most possible anticancer metabolites in Coscinoderma sp. and to point a probable molecular target for them. The details for PASS were described in Supplementary Material and

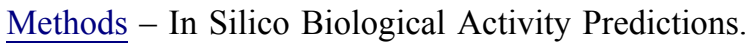

\section{Molecular Docking Experiments}

Molecular docking was carried out utilizing Autodock Vina software. ${ }^{23}$ The details were described in Supplementary Material and Methods - Molecular Docking Experiments.

\section{Statistical Analysis}

The details were described Supplementary Material and Methods - Statistical analysis.

\section{Results and Discussion}

\section{Chemical Dereplication of Coscinoderma sp} Analyzing Coscinoderma sp. crude extract, several hits were proposed (Table 1, Figures 1-3). The molecular ion mass peaks at $\mathrm{m} / z$ 305.2117, and $317.2117[\mathrm{M}+\mathrm{H}]^{+}$, for the predicted molecular formulas $\mathrm{C}_{19} \mathrm{H}_{28} \mathrm{O}_{3}$ and $\mathrm{C}_{20} \mathrm{H}_{28} \mathrm{O}_{3}$ gave hits of spongian diterpenes, Ent-13-norisocopalen-15-al-18-oic acid 1, and Spongia 13(16),14-dien-19-oic acid 2, respectively, that were previously isolated from Coscinoderma mathewsi. ${ }^{24}$ The mass ion peaks at $\mathrm{m} / \mathrm{z} 330.1243,333.2066,349.2015$, $363.2171,369.2794$, and 385.2743 , corresponding to the suggested molecular formulas $\mathrm{C}_{20} \mathrm{H}_{15} \mathrm{~N}_{3} \mathrm{O}_{2}, \quad \mathrm{C}_{20} \mathrm{H}_{28} \mathrm{O}_{4}$, $\mathrm{C}_{20} \mathrm{H}_{28} \mathrm{O}_{5}, \mathrm{C}_{21} \mathrm{H}_{30} \mathrm{O}_{5}, \mathrm{C}_{25} \mathrm{H}_{36} \mathrm{O}_{2}$, and $\mathrm{C}_{25} \mathrm{H}_{36} \mathrm{O}_{3}[\mathrm{M}+\mathrm{H}]^{+}$, fit indole alkaloid coscinamide $\mathrm{A}$; debromo 3 , spongian diterpenes derivatives, 15-Oxospongi-13-en-19-oic acid 4, 15 -Hydroxy-16-oxospongi-13-en-19-oic acid 5, 15-methoxy -16-oxospongi-13-en-19-oic acid 6, and sesterterpenoid coscinafuran $\mathbf{7}$, coscinalactone $\mathbf{8}$, that were previously isolated from Coscinoderma mathewsi, and other Coscinoderma spp. respectively. ${ }^{24-26}$ Also, the mass ion peaks at $m / z$ 408.0348, 415.3212, 427.3212, 429.3369, and 431.3525 corresponding to the suggested molecular formulas $\mathrm{C}_{20} \mathrm{H}_{14} \mathrm{BrN}_{3} \mathrm{O}_{2}, \mathrm{C}_{27} \mathrm{H}_{42} \mathrm{O}_{3}$, $\mathrm{C}_{28} \mathrm{H}_{42} \mathrm{O}_{3}, \mathrm{C}_{28} \mathrm{H}_{44} \mathrm{O}_{3}$, and $\mathrm{C}_{28} \mathrm{H}_{46} \mathrm{O}_{3}[\mathrm{M}+\mathrm{H}]^{+}$fit an indole alkaloid, and antiplasmodial sterol derivative compounds coscinamide A 9, $5 \alpha, 8 \alpha$-epidioxycholesta-6-en- $3 \beta$-ol 10, $5 \alpha, 8 \alpha$ epidioxy-24-methylcholesta-6,9(11) 24(28)-trien-3 $\beta$-ol 11, $5 \alpha, 8 \alpha$-epidioxycholesta-6,24(28)-dien-3 $\beta$-o1 12, and (24S)$5 \alpha, 8 \alpha$-epidioxy-24-methylcholesta-6-en $3 \beta$-ol 13, that was previously isolated from Coscinoderma mathewsi, and other Coscinoderma sp., respectively. ${ }^{25,27}$ Moreover, the molecular ion mass peaks at $m / z 451.2518$, and $451.3576[\mathrm{M}+\mathrm{H}]^{+}$, for the predicted molecular formulas $\mathrm{C}_{25} \mathrm{H}_{38} \mathrm{O}_{5} \mathrm{~S}$ and $\mathrm{C}_{31} \mathrm{H}_{46} \mathrm{O}_{2}$ gave hits of the serine protease inhibitor methylherbipoline salt, suvanine 14, and cytotoxic suvanine analog coscinoquinol 15, respectively, that were previously isolated from Coscinoderma mathewsi. ${ }^{28,29}$ The ion mass peaks at $\mathrm{m} /$ $z$ 475.2494, 524.2682, 549.3250, and 566.3151 [M+H] $]^{+}$for the predicted molecular formulas $\mathrm{C}_{25} \mathrm{H}_{39} \mathrm{NaO}_{5} \mathrm{~S}, \mathrm{C}_{27} \mathrm{H}_{41} \mathrm{NO}_{7}$ $\mathrm{S}, \mathrm{C}_{31} \mathrm{H}_{48} \mathrm{O}_{6} \mathrm{~S}$, and $\mathrm{C}_{30} \mathrm{H}_{47} \mathrm{NO}_{7} \mathrm{~S}$ gave hits of the halisulfate 1 16, coscinolactam A 17, halisulfate 2 18, cytotoxic Suvanine analog derivatives, which were previously isolated from Coscinoderma mathewsi, ${ }^{29}$ and another serine protease inhibitor methylherbipoline salt, coscinolactam A; 1'S-isopropyl, 
Table I Dereplicated Metabolites from LC-HRESIMS Analysis of Coscinoderma sp. Crude Extract

\begin{tabular}{|c|c|c|c|c|c|}
\hline No. & Metabolites Name & Original Source & MF & RT (min) & $\mathbf{m} / \mathbf{z}$ \\
\hline 1 & Ent-13-norisocopalen-I5-al-18-oic acid & Coscinoderma mathewsi & $\mathrm{C}_{19} \mathrm{H}_{28} \mathrm{O}_{3}$ & 7.8187 & 305.2117 \\
\hline 2 & Spongia |3(16), I4-dien-19-oic acid & Coscinoderma mathewsi & $\mathrm{C}_{20} \mathrm{H}_{28} \mathrm{O}_{3}$ & 7.6540 & 317.2117 \\
\hline 3 & Coscinamide A; Debromo & Coscinoderma spp. & $\mathrm{C}_{20} \mathrm{H}_{15} \mathrm{~N}_{3} \mathrm{O}_{2}$ & 6.0123 & 330.1243 \\
\hline 4 & 15-Oxospongi-13-en-19-oic acid & Coscinoderma mathewsi & $\mathrm{C}_{20} \mathrm{H}_{28} \mathrm{O}_{4}$ & 7.58040 & 333.2066 \\
\hline 5 & I5 -Hydroxy-16-oxospongi-13-en-19-oic acid & Coscinoderma mathewsi & $\mathrm{C}_{20} \mathrm{H}_{28} \mathrm{O}_{5}$ & 7.56501 & 349.2015 \\
\hline 6 & I5-Methoxy-16-oxospongi-I3-en-I9-oic acid & Coscinoderma mathewsi & $\mathrm{C}_{21} \mathrm{H}_{30} \mathrm{O}_{5}$ & 7.5908 & 363.2171 \\
\hline 7 & Coscinafuran & Coscinoderma mathewsi & $\mathrm{C}_{25} \mathrm{H}_{36} \mathrm{O}_{2}$ & 6.7003 & 369.2794 \\
\hline 8 & Coscinalactone & Coscinoderma mathewsi & $\mathrm{C}_{25} \mathrm{H}_{36} \mathrm{O}_{3}$ & 14.5149 & 385.2743 \\
\hline 9 & Coscinamide A & Coscinoderma spp. & $\mathrm{C}_{20} \mathrm{H}_{14} \mathrm{BrN}_{3} \mathrm{O}_{2}$ & 5.9845 & 408.0348 \\
\hline 10 & $5 \alpha, 8 \alpha$-Epidioxycholesta-6-en- $3 \beta$-ol & Coscinoderma spp. & $\mathrm{C}_{27} \mathrm{H}_{42} \mathrm{O}_{3}$ & 15.6207 & 415.3212 \\
\hline 11 & $5 \alpha, 8 \alpha$-Epidioxy-24-methylcholesta-6,9(I I) 24(28)-trien-3 $\beta$-ol & Coscinoderma spp. & $\mathrm{C}_{28} \mathrm{H}_{42} \mathrm{O}_{3}$ & 15.6109 & 427.3212 \\
\hline 12 & $5 \alpha, 8 \alpha$-Epidioxycholesta-6,24(28)-dien-3 $\beta$-ol & Coscinoderma spp. & $\mathrm{C}_{28} \mathrm{H}_{44} \mathrm{O}_{3}$ & 15.6004 & 429.3369 \\
\hline 13 & (24S)-5 $\alpha, 8 \alpha$-Epidioxy-24-methylcholesta-6-en $3 \beta$-ol & Coscinoderma spp. & $\mathrm{C}_{28} \mathrm{H}_{46} \mathrm{O}_{3}$ & 15.6114 & 431.3525 \\
\hline 14 & Suvanine & Coscinoderma mathewsi & $\mathrm{C}_{25} \mathrm{H}_{38} \mathrm{O}_{5} \mathrm{~S}$ & 4.5508 & 451.2518 \\
\hline 15 & Coscinoquinol & Coscinoderma mathewsi & $\mathrm{C}_{31} \mathrm{H}_{46} \mathrm{O}_{2}$ & 6.5731 & 451.3576 \\
\hline 16 & Halisulfate I & Coscinoderma mathewsi & $\mathrm{C}_{25} \mathrm{H}_{39} \mathrm{NaO}_{5} \mathrm{~S}$ & 4.5440 & 475.2494 \\
\hline 17 & Coscinolactam A & Coscinoderma mathewsi & $\mathrm{C}_{27} \mathrm{H}_{41} \mathrm{NO}_{7} \mathrm{~S}$ & 5.6890 & 524.2682 \\
\hline 18 & Halisulfate 2 & Coscinoderma mathewsi & $\mathrm{C}_{31} \mathrm{H}_{48} \mathrm{O}_{6} \mathrm{~S}$ & 4.5409 & 549.3250 \\
\hline 19 & Coscinolactam A; I'S-isopropyl, 25-deoxo, 19-oxo & Coscinoderma mathewsi & $\mathrm{C}_{30} \mathrm{H}_{47} \mathrm{NO}_{7} \mathrm{~S}$ & 5.9013 & 566.3151 \\
\hline 20 & Coscinosulfate & Coscinoderma mathewsi & $\mathrm{C}_{31} \mathrm{H}_{47} \mathrm{NaO}_{6} \mathrm{~S}$ & 7.8758 & 571.3077 \\
\hline
\end{tabular}

Abbreviations: MF, molecular formula; RT, retention time; min, minute; m/z, mass-to-charge-ratio.

25-deoxo, 19-oxo 19, that also previously isolated from Coscinoderma mathewsi. ${ }^{28}$ Another major ion peak with the $m / z$ value of $571.3077[\mathrm{M}+\mathrm{H}]^{+}$with molecular formula
$\mathrm{C}_{31} \mathrm{H}_{47} \mathrm{NaO}_{6} \mathrm{~S}$ was detected and dereplicated as coscinosulfate 20, which was isolated earlier from Coscinoderma mathewsi. ${ }^{28}$

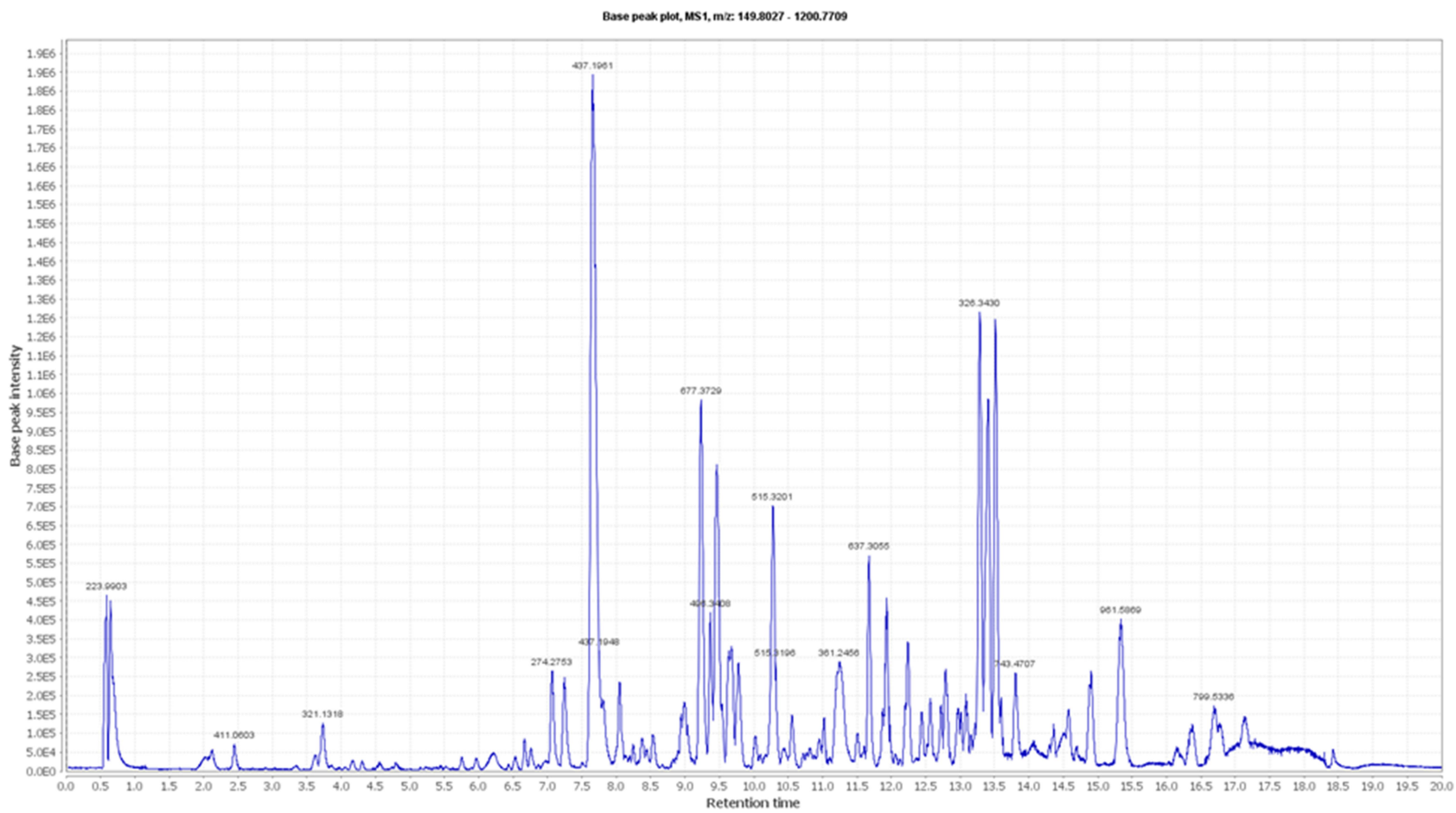

Figure I LC-HRESIMS chromatogram of the dereplicated metabolites of Coscinoderma sp. (positive). 


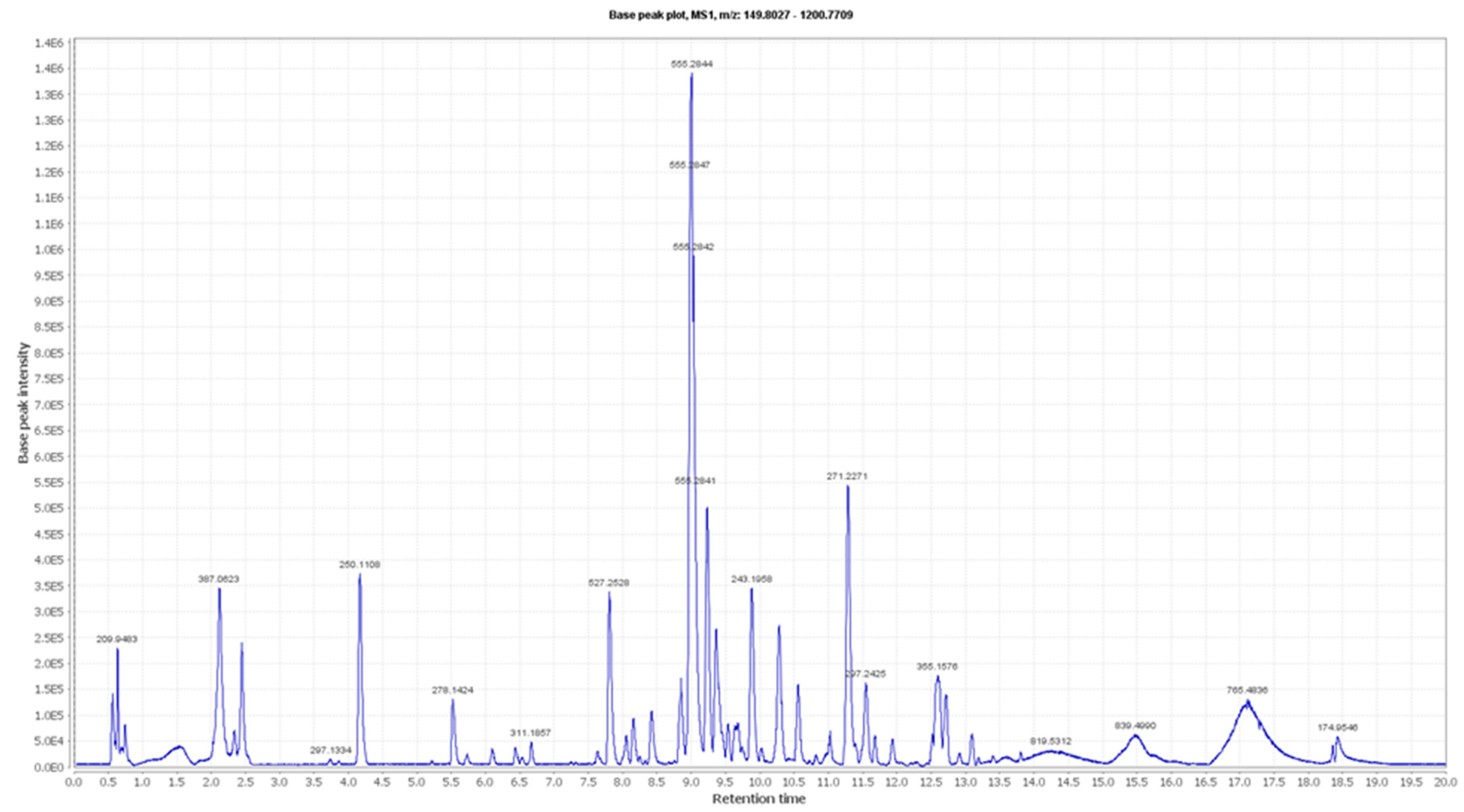

Figure 2 LC-HRESIMS chromatogram of the dereplicated metabolites of Coscinoderma sp. (negative).

\section{Coscinoderma sp.-Containing Liposomes}

Morphology of the prepared formulations reveals that vesicular liposomes are successfully prepared (Figure 4A and B). The vesicles are small and homogenously distributed (size $=$ $131 \pm 12.3, \mathrm{PDI}=0.222$ ). The vesicles have a zeta potential of $20.8 \pm 2.3$.

Thermogravimetric analysis was carried out to evaluate the potential of encapsulating the extract within the formulated liposomes on the enhancement of the physical and chemical stability of the entrapped Coscinoderma extract as a function of temperature. TGA curves for empty liposomes, Coscinoderma and Coscinoderma liposomes are shown in Figure 5. Upon heating from $30^{\circ} \mathrm{C}$ to $450^{\circ} \mathrm{C}$, about $72.5 \%$ and $16.3 \%$ weight loss was observed at a temperature of $169^{\circ}$ C for Coscinoderma extract and Coscinoderma liposomes, respectively. Results show the enhanced thermal stability of the entrapped cargo due to liposomal encapsulation.

To estimate the possible interactions between the components of the extract and those of the membrane bilayer of liposomes, FTIR spectra of Coscinoderma extract, empty liposomes, and Coscinoderma liposomes were studied (Figure 6). The FTIR spectrum of Coscinoderma extract contains principle bands at 3409, 1622, 1210, and 1507 , and that of empty liposomes contains bands at 2907, 1736, 1459, 1234, and 1060. The FTIR spectrum of
Coscinoderma liposomes contains similar bands to those contained in both free extract and empty liposome spectra, indicating that the encapsulation of Coscinoderma extract within the prepared liposomes did not form new linkages.

\section{Target Prediction and Docking Analysis}

Neural networks-based biological activity predictions that depend on artificial intelligence and machine learning processing along with other computer-aided drug design approaches have become widely accepted as an integral step during the drug discovery process. ${ }^{30,31}$

Such in silico-based procedures could-be employed in drug discovery from natural sources, where they can register a set of possibly active hits among a complex mixture of other metabolites present in a given-natural crude extract. ${ }^{32}$

To putatively assign the most probable metabolites that might be associated with the anticancer activity of Coscinoderma sp., we submitted the most abundant metabolites (Figure 3) to a neural network-based prediction software PASS. This software search algorithm depends on the structural analogy of a great number of inhibitors recorded for a broad area of biological targets. ${ }^{23}$

As shown in Figure 7A, among the detected metabolites in Coscinoderma sp., compounds 1-15 that represented about $76.6 \%$ of the detected compounds, were predicted to exhibit 
<smiles>CC12C=C(C=O)CCC1C1(C)CCC[C@](C)(C(=O)O)C1CC2</smiles>

1

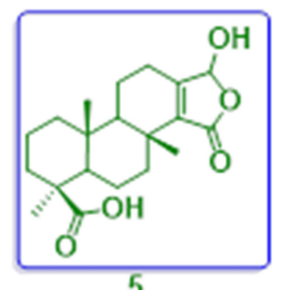

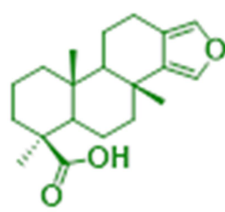

2

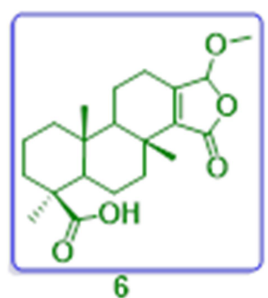

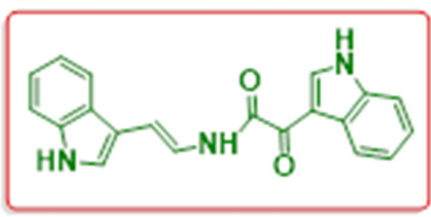

3

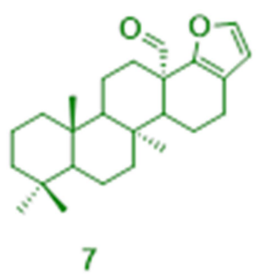<smiles>CC1(C)CCC[C@]2(C)C3CCC4(C=O)C5OC(=O)C=C5CCC4[C@]3(C)CC[C@@H]12</smiles>

8<smiles>O=C(N/C=C/c1c[nH]c2cc(Br)ccc12)C(=O)c1c[nH]c2ccccc12</smiles>

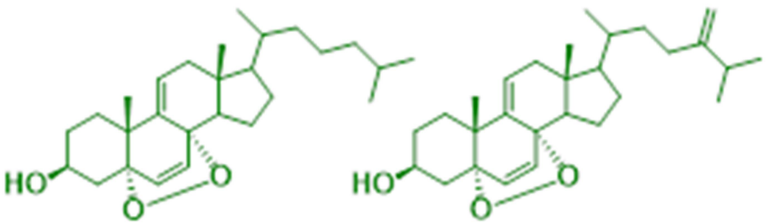

10

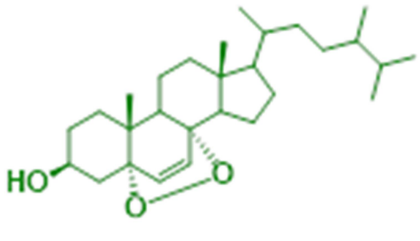

13<smiles>CC1(C)CCCC2(C)C1CC[C@]1(C)C2CC/C(=C\OS(=O)(=O)O)[C@@H]1CCc1ccoc1</smiles>

14<smiles>CC1(C)CCCC2(C)C1CCC1(C)C(CCC3=CCN(CC(=O)O)C3=O)C(=COS(=O)(=O)O)CCC12</smiles>

17

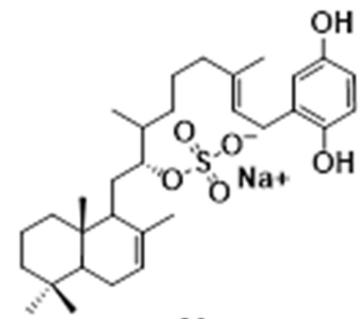

20

Figure 3 Metabolites putatively identified by LC-HRESIMS analysis of CE. Green metabolites showed the highest scores by PASS-based in silico predictions (anticancer, phosphatase inhibitors, and Pin-I inhibitors for compounds 3 and 9). Compounds inside blue rectangles were further verified by docking analysis against SHP2. Compounds inside red rectangles were further verified by docking analysis against Pin-I. 

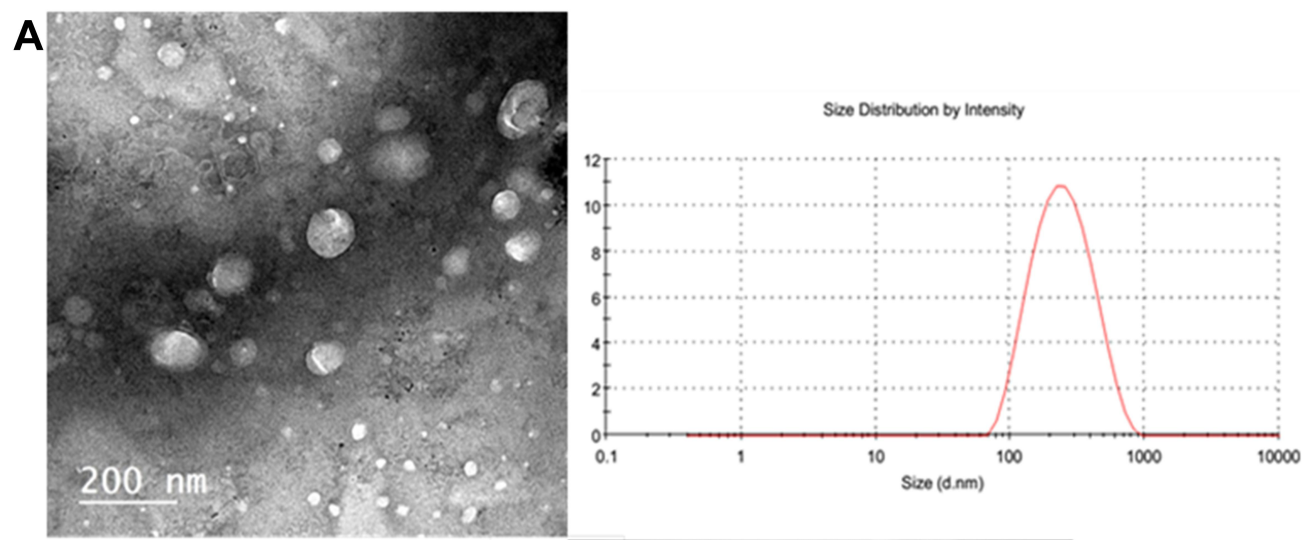

B

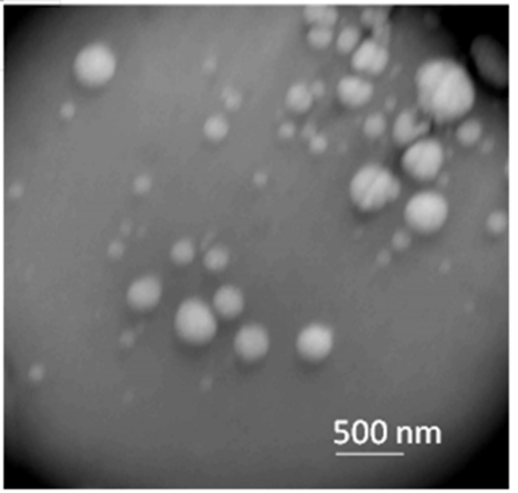

Figure 4 (A) TEM images and size distribution of Coscinoderma sp.-containing liposomes, (B) TEM image of empty liposomes.

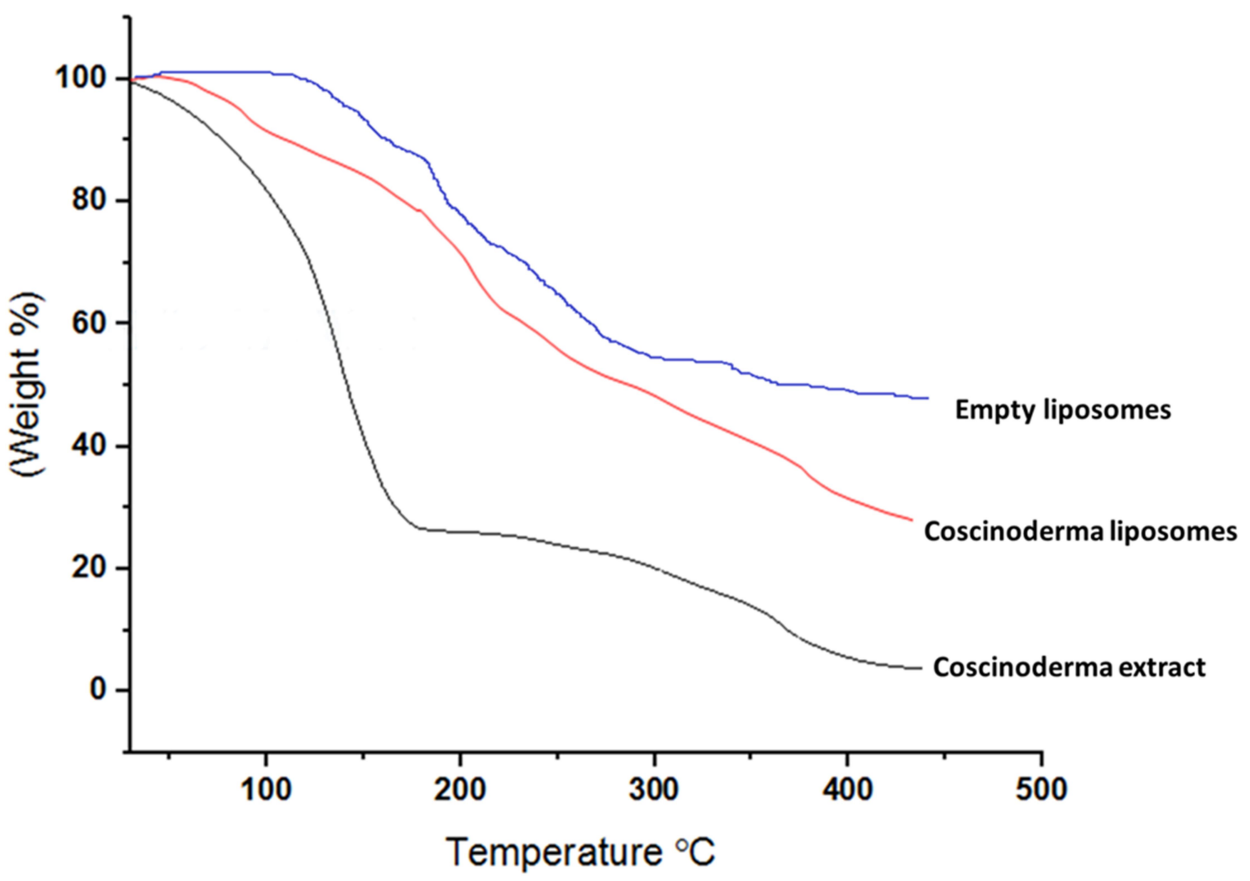

Figure 5 Thermogravimetric analysis (TGA) of empty liposomes, Coscinoderma extract and Coscinoderma liposomes. 

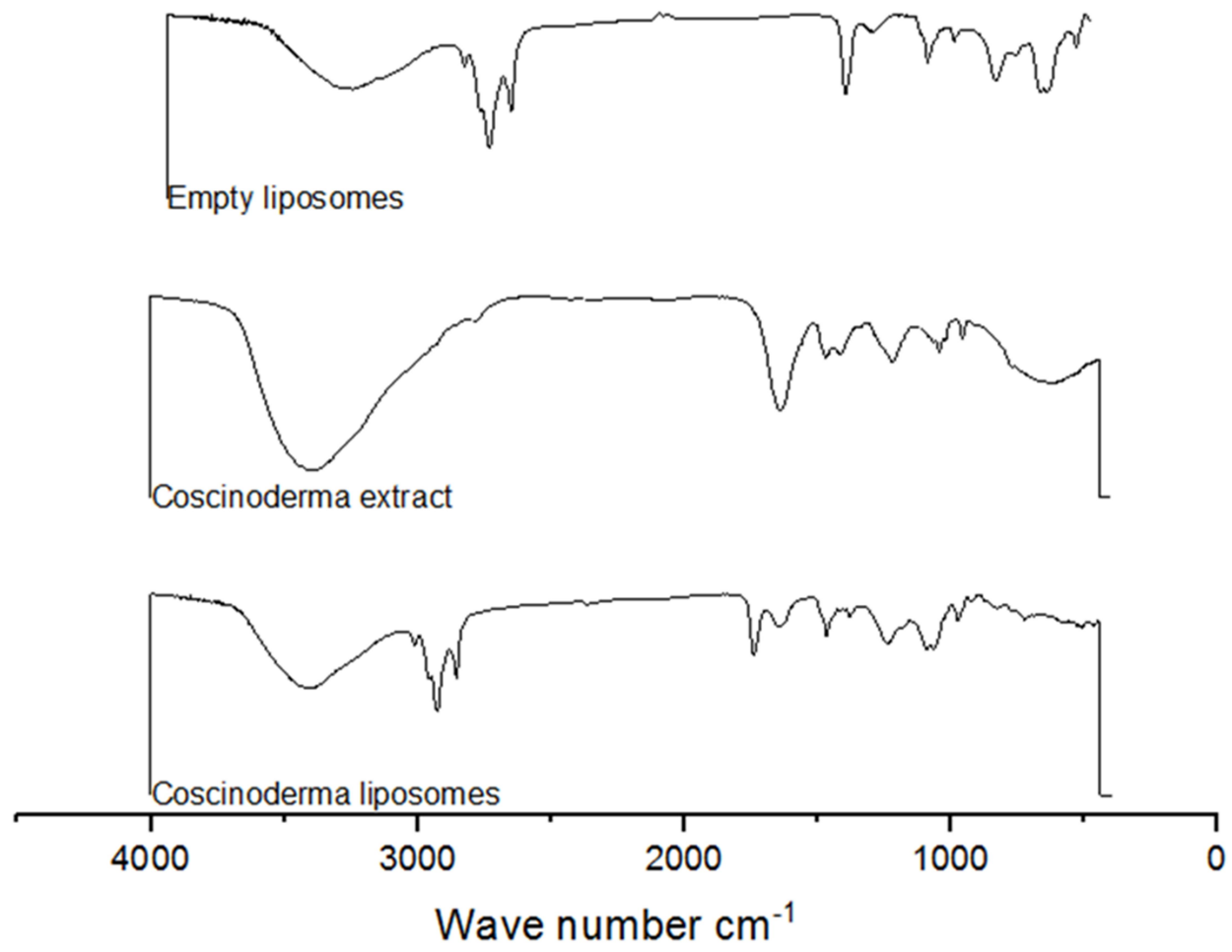

Figure 6 FTIR of empty liposomes, Coscinoderma extract, and Coscinoderma liposomes.

antiproliferative activity $(\mathrm{Pa}>0.5)$. Moreover, human phosphatase was suggested to be the probable target for them except for metabolites $\mathbf{3}$ and $\mathbf{9}$ that were predicted to target peptidyl prolyl cis-trans-isomerase NIMA interacting-1 (PIN-1). Accordingly, we searched for human phosphatases that are strongly linked to tumorigenesis. We found the non-receptorprotein-tyrosine-phosphatase (SHP2) along with proteintyrosine-phosphatases (PRL-1, -2, and -3) are currently well established as oncogenic phosphatases. ${ }^{33}$ These proteins are known to regulate cell survival and proliferation, through activation of the RAS-ERK (extracellular signal-regulated kinase) signaling pathway. ${ }^{33}$ On the other hand, Pin-1 is a key effector in Ras signaling and is frequently overexpressed in many types of cancers with poor prognosis. ${ }^{34}$ Consequently, we further assessed the PASS predictions by molecular docking experiments against the oncogenic phosphatases (ie, SHP2, and PRL-1 to -3) together with Pin-1. Among the metabolites that were predicted to mediate an anticancer activity by the inhibition of oncogenic phosphatases (Figures 7B and 8), only compounds 4-6 achieved good binding affinities (Figure 5B; < $-5 \mathrm{kcal} / \mathrm{mol}$ ) toward SHP2, that was also higher than that of the co-crystallized inhibitor $(-8.5 \mathrm{kcal} / \mathrm{mol}$ for compounds $\mathbf{4 - 6}$, and $-7.1 \mathrm{kcal} / \mathrm{mol}$ for the co-crystal inhibitor). Additionally, the mode of interaction of these metabolites (ie, 4-6) was comparable with this of the reported co-crystallized inhibitor. ${ }^{35}$ The most important interactions inside the SHP2's binding site were H-bonding, particularly with ARG11, PHE-113, and GLU-250, amino acids that were also involved in the interaction with the co-crystallized inhibitor (Figure 8).

Regarding Pin-1, both metabolites 3 and 9 were predicted to target this oncoprotein, and they were also achieved good binding affinities toward Pin-1 with a mode of interactions convergent to that of the co-crystallized inhibitor (Figures 7B and 9). ${ }^{36}$ Both compounds 3 and 9 interacted through H-bonding with LYS-63, ARG-69, ASP-112, and SER-154. Moreover, they exhibited two hydrophobic interactions with LEU-122 and PHE-134 (Figure 9). These bis-indole derivatives have been previously identified as anticancer agents. ${ }^{37}$

\section{Antiproliferative Activity of the Crude Extract}

According to the results of the in silico analysis, Coscinoderma sp.'s crude extract has a great anticancer potential. Consequently, it was in vitro screened for its potential as antiproliferative against hepatic, breast, and colorectal carcinoma cell lines (HepG2, MCF-7, and Caco-2, respectively). Results revealed that the crude extract was able to inhibit the 

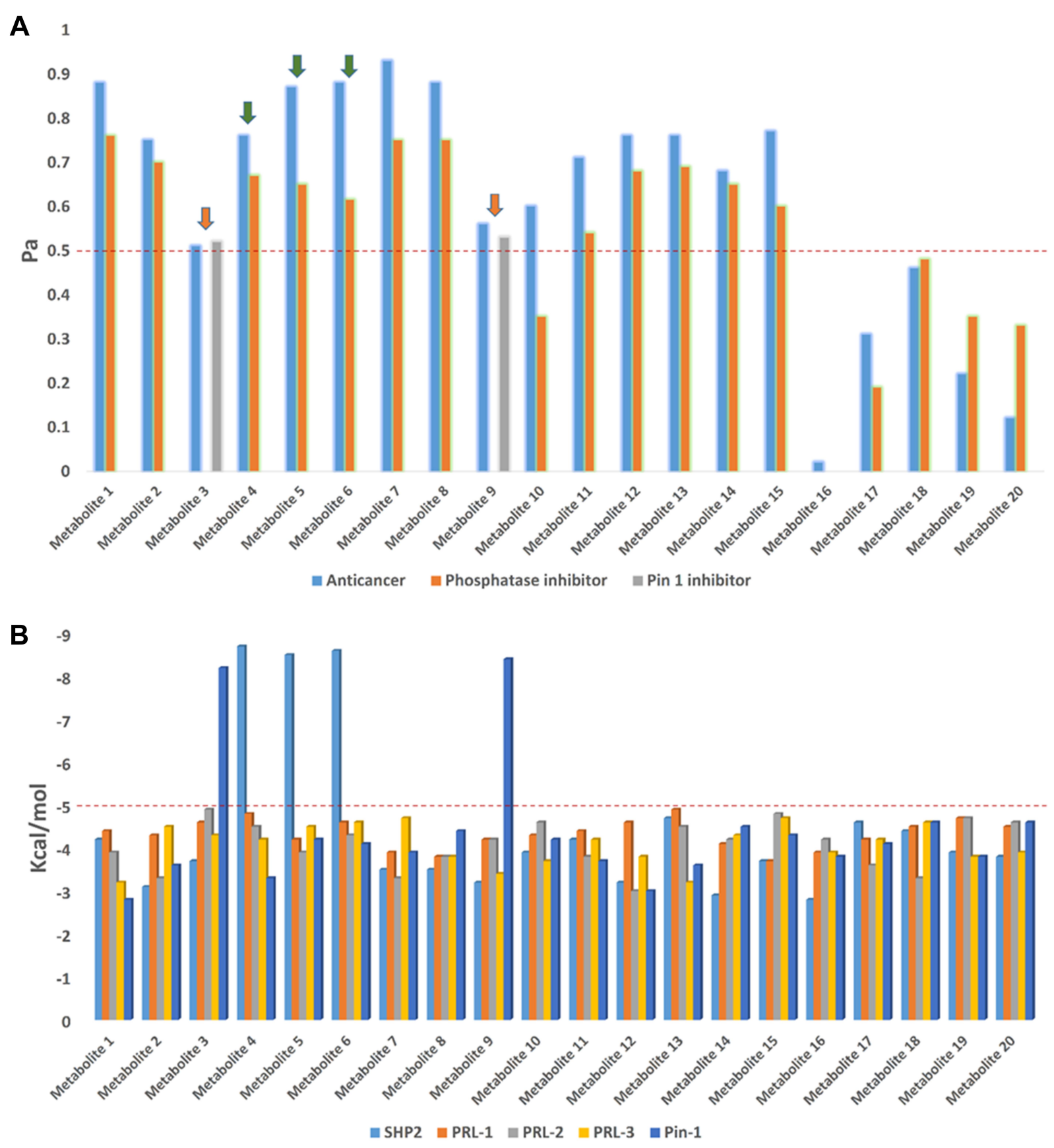

Figure 7 (A) PASS prediction scores of metabolites I-20. Pa scores $>0.5$ indicated high-possible experimental activity. Blue columns are for the scores of antiproliferative activity, while the orange columns are for the phosphatase inhibitory activity, and gray columns are for the Pin-I inhibitory activity. Metabolites 4-6 (assigned by green arrows) showed good binding affinities toward SHP2, while metabolites $\mathbf{3}$ and $\mathbf{9}$ (assigned by orange arrows) showed good binding affinities toward Pin-I. (B) Binding affinities of compounds I-20 against SHP2, PRL-I-3, and Pin-I.

growth of all tested cell lines moderately with $\mathrm{IC}_{50}$ values ranged from $10.7 \pm 0.05$ to $12.4 \pm 0.10 \mu \mathrm{g} / \mathrm{mL}(p<0.001)$, respectively (Table 2). Doxorubicin ( $\mathrm{IC}_{50} 4.3,3.8,3.4 \mu \mathrm{g} / \mathrm{mL}$, respectively) was used as a positive control (Table 2).

To gain more insight into the effect of encapsulation within the liposomal formulation on the improvement of the antiproliferative activity of the components in Coscinoderma sp. crude extract, MTT assay was carried out for the extract-containing liposomes. The $\mathrm{IC}_{50}$ against HepG2, MCF-7, and Caco-2 cell lines was determined for the three investigated cell lines. Results show that the sensitivity of the three investigated cell lines 


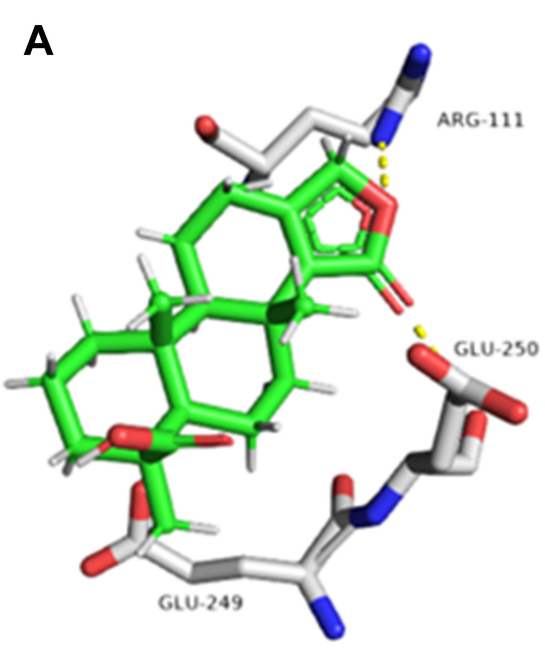

C

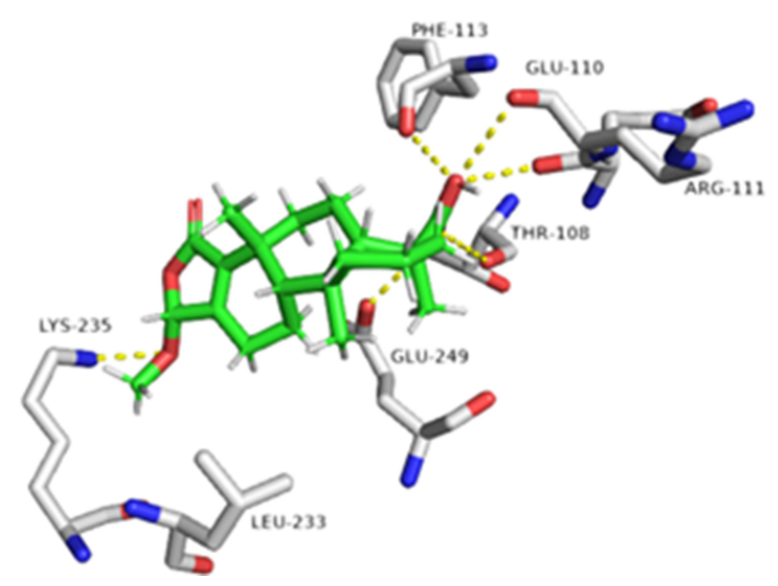

D

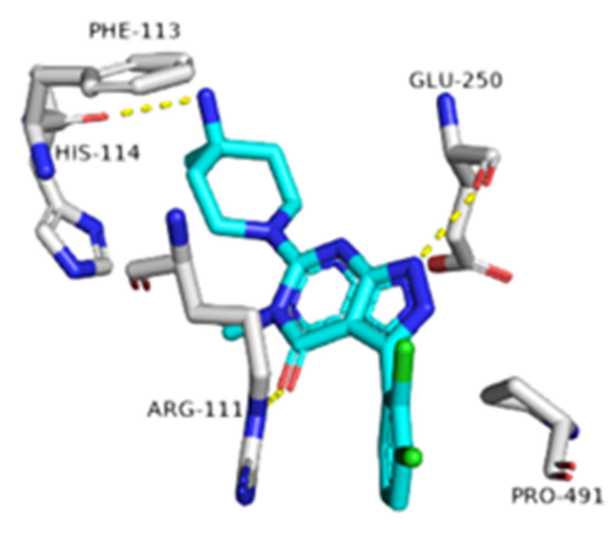

Figure 8 Binding modes of metabolites 4-6 together with the co-crystallized inhibitor (A-D, respectively) inside the binding site of SHP2.

was significantly enhanced after liposomal formulation. Where $\mathrm{IC}_{50}$ of the crude extract-containing liposomes against HepG2, MCF-7, and Caco-2 has significantly decreased to $2.2 \pm 0.31,4.1 \pm 0.25$, and $1.7 \pm 0.18 \mu \mathrm{g} / \mathrm{mL}$, respectively $(p<0.001)$. Cell viability of the three investigated cell lines was evaluated for Coscinodermacontaining liposomes $\left(\right.$ at $\mathrm{IC}_{50}$ ) and their corresponding empty liposomes to exclude the cytotoxic effect of the phospholipid membrane (Figure 10). This is consistent with previous studies that reported the impact of nanocarriers on the enhancement of the cellular uptake and accessibility of the entrapped cargo. ${ }^{38-40}$ Nanomaterials with smaller particle sizes are easier to be up taken via endocytosis. ${ }^{41}$ Since the low water solubility of extract components can be an obstacle against availability for absorption and cellular uptake, ${ }^{42,43}$ enhancement of solubilization of the extract components, achieved by encapsulation, may have an important role in the improved cytotoxic effect against the cell lines under investigation. ${ }^{44}$ Favored uptake by interstitial leaky vasculature of tumor tissues can be another scenario for the accelerated cellular internalization. ${ }^{45}$ Besides, the presence of cholesterol contributes to the cellular uptake of liposomes. ${ }^{46}$ Clinically, formulating such cytotoxic payload into a nano-carrier system, that would entrap both the hydrophilic and the lipophilic components with the improvement of cellular uptake, would be of great therapeutic value especially if designed as a longcirculating formulation, which is the scope of our upcoming work. 


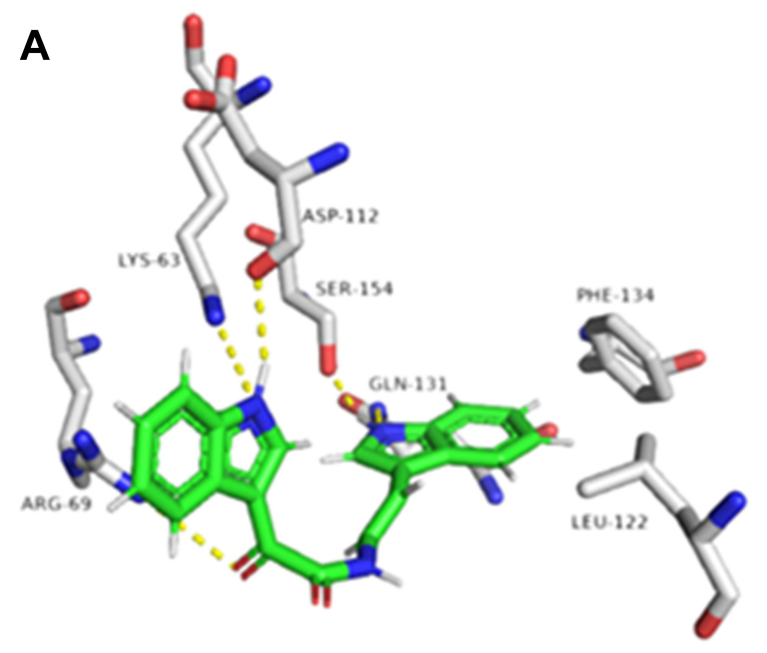

B

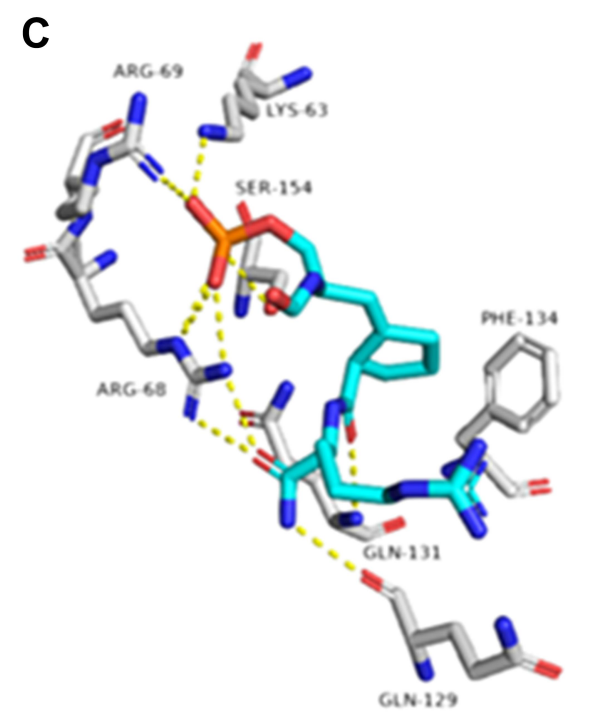

Figure 9 Binding modes of metabolites 3 and 9 together with the co-crystallized inhibitor (A-C, respectively) inside the binding site of Pin-I.

\section{Conclusion}

In the present study, the metabolomic profiling of Coscinoderma sp. crude extract dereplicated 20 compounds,

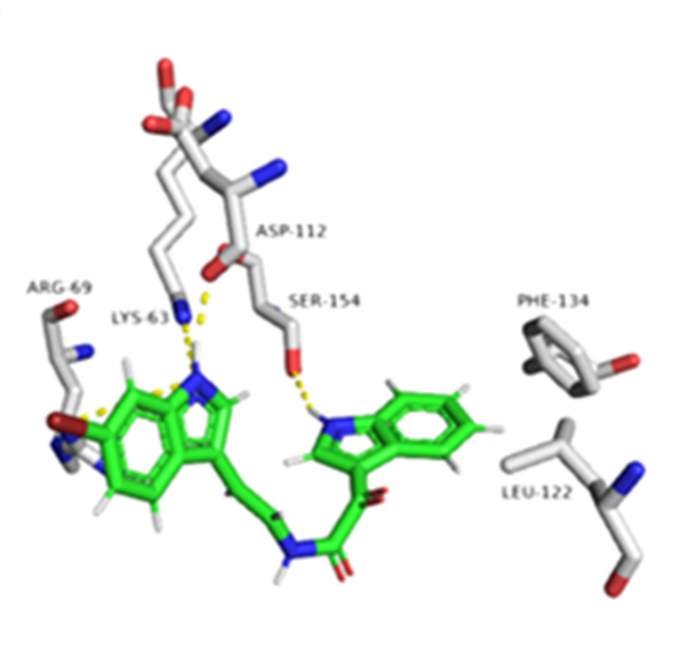

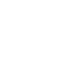




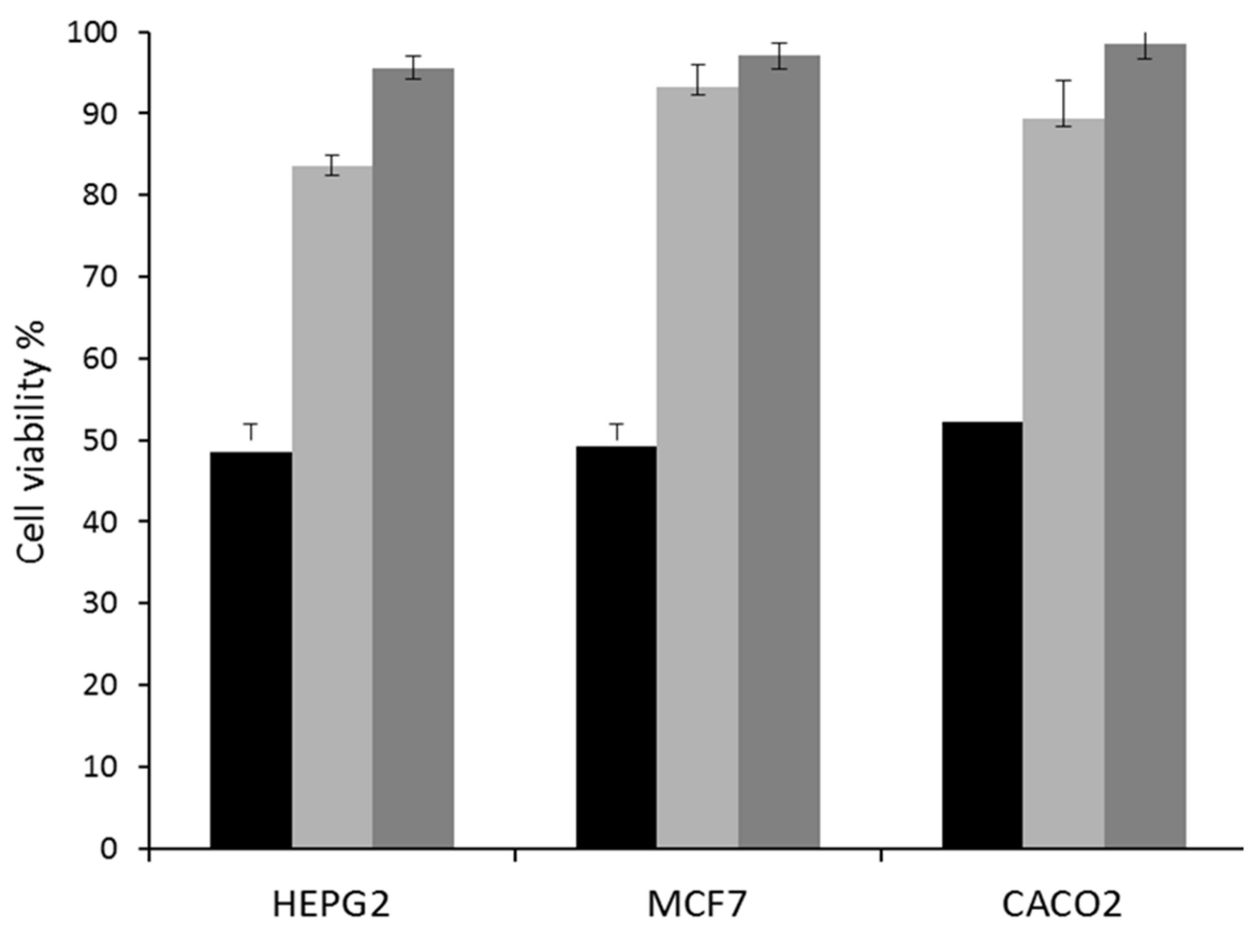

Coscinoderma liposomes ampty liposomes control

Figure 10 Cell viability of HepG2, MCF7, and Caco-2 cell lines at IC $_{50}$ of Coscinoderma liposomes and the corresponding empty liposomes.

Salt. Coscinoderma sp. crude extract showed moderate antiproliferative activities against HepG2, MCF-7, and Caco-2. The improved delivery to the studied cell lines was achieved by the entrapment of Coscinoderma sp. crude extract within liposomal vesicles. Although our results mainly denote the in vitro MTT experiments, liposomal entrapment of the extract seems to be a promising approach to enhance the antiproliferative potential of the extract components. PASS in silico predicted compounds 1-15 as antiproliferative which target both SHP2, and Pin-1. Further isolation of the active components from the crude extract together with the in vivo studies are in progress to find out the applicability of such formulation as an anticancer therapeutic approach.

\section{Acknowledgments}

The writers would prefer to give their heartfelt gratitude to the central laboratory at Jouf University to aid this research.

\section{Funding}

The writers give their gratitude to the Deputyship for Research and Innovation, Ministry of Education in Saudi Arabia for supporting this work through the project number " $375213500 "$ "

\section{Disclosure}

The authors declared no conflict of interest for this work.

\section{References}

1. Henseler C, Nordström MC, Törnroos A, et al. Coastal habitats and their importance for the diversity of benthic communities: a species-and trait-based approach. Estuar Coast Shelf Sci. 2019;226:106272. doi:10.1016/j.ecss.2019.106272

2. Farag MA, Fekry M, Al-Hammady M, et al. Cytotoxic effects of Sarcophyton sp. soft corals-Is there a correlation to their NMR fingerprints? Mar Drugs. 2017;15:211. doi:10.3390/md15070211

3. Alves A, Sousa E, Kijjoa A, Pinto M. Marine-derived compounds with potential use as cosmeceuticals and nutricosmetics. Molecules. 2020;25:2536. doi:10.3390/molecules 25112536

4. Avila C, Angulo-Preckler C. Bioactive compounds from marine heterobranchs. Mar Drugs. 2020;18:657. doi:10.3390/md18120657

5. Musa A, Al-muaikel N, Abdel-Bakky M. Phytochemical and pharmacological evaluations of ethanolic extract of. Bassia Eriophora, Bassia Eriophora Der Pharma Chem. 2016;8:169-178.

6. Mioso R, Marante F, Bezerra R, et al. Cytotoxic compounds derived from marine sponges. A review (2010-2012). Molecules. 2017;22:208. doi:10.3390/molecules22020208

7. Meisner D, Mezei M. Liposome ocular delivery systems. Adv Drug Delivery Rev. 1995;16:75-93. doi:10.1016/0169-409X(95)00016-Z

8. Refaat H, Naguib YW, Elsayed M, Sarhan HA, Alaaeldin E. Modified spraying technique and response surface methodology for the preparation and optimization of propolis liposomes of enhanced anti-proliferative activity against human melanoma cell line A375. Pharmaceutics. 2019;11:558. doi:10.3390/pharmaceutics11110558 
9. Mostafa M, Alaaeldin E, Aly UF, Sarhan HA. Optimization and characterization of thymoquinone-loaded liposomes with enhanced topical anti-inflammatory activity. AAPS PharmSciTech. 2018;19:3490-3500. doi:10.1208/s12249-018-1166-1

10. Refaat H, Mady FM, Sarhan HA, Rateb HS, Alaaeldin E. Optimization and evaluation of propolis liposomes as a promising therapeutic approach for COVID-19. I $J$ pharmaceutics. 2020;120028.

11. Alaaeldin E, Abu Lila AS, Ando $\mathrm{H}$, et al. Co-administration of liposomal 1-OHP and PEGylated TS shRNA-lipoplex: a novel approach to enhance anti-tumor efficacy and reduce the immunogenic response to RNAi molecules. $J$ Controlled Release. 2017;255:210-217. doi:10.1016/j.jconrel.2017.04.040

12. Singh AV, Hosseinidoust Z, Park B-W, Yasa O, Sitti M. Microemulsion-based soft bacteria-driven microswimmers for active cargo delivery. ACS Nano. 2017;11:9759-9769. doi:10.1021/ acsnano.7b02082

13. Rajabi M, Adeyeye M, Mousa SA. Peptide-conjugated nanoparticles as targeted anti-angiogenesis therapeutic and diagnostic in cancer. Cur Med Chem. 2019;26:5664-5683. doi:10.2174/ 0929867326666190620100800

14. Fan Y, Marioli M, Zhang K. Analytical characterization of liposomes and other lipid nanoparticles for drug delivery. J Pharm Biomed Anal. $2020 ; 113642$.

15. Juszkiewicz K, Sikorski AF, Czogalla A. Building Blocks to Design Liposomal Delivery Systems. Int J Mol Sci. 2020;21:9559. doi:10.3390/ijms21249559

16. Alaaeldin E, Abu Lila AS, Moriyoshi N, et al. The co-delivery of oxaliplatin abrogates the immunogenic response to PEGylated siRNA-lipoplex. Pharm Res. 2013;30:2344-2354. doi:10.1007/ s11095-013-1078-4

17. Charcosset C, Juban A, Valour J-P, Urbaniak S, Fessi H. Preparation of liposomes at large scale using the ethanol injection method: effect of scale-up and injection devices. Chem Eng Res Des. 2015;94:508-515. doi:10.1016/j.cherd.2014.09.008

18. Jaafar-Maalej C, Diab R, Andrieu V, Elaissari A, Fessi H. Ethanol injection method for hydrophilic and lipophilic drug-loaded liposome preparation. J Liposome Res. 2010;20:228-243. doi:10.3109/ 08982100903347923

19. Abdelmohsen UR, Cheng C, Viegelmann C, et al. Dereplication strategies for targeted isolation of new antitrypanosomal actinosporins A and B from a marine sponge associated-Actinokineospora sp. EG49 Mar Drugs. 2014;12:1220-1244. doi:10.3390/md12031220

20. Shamikh YI, El Shamy AA, Gaber Y, et al. Actinomycetes from the Red Sea sponge Coscinoderma mathewsi: isolation, diversity, and potential for bioactive compounds discovery. Microorganisms. 2020;8:783. doi:10.3390/microorganisms8050783

21. Alzarea SI, Elmaidomy AH, Saber H, et al. Potential anticancer lipoxygenase inhibitors from the red sea-derived brown algae sargassum cinereum: an in-silico-supported In-Vitro Study. Antibiotics. 2021;10:416. doi:10.3390/antibiotics 10040416

22. Lagunin A, Stepanchikova A, Filimonov D, Poroikov V. PASS: prediction of activity spectra for biologically active substances. Bioinformatics. 2000;16:747-748. doi:10.1093/bioinformatics/ 16.8 .747

23. Seeliger D, de Groot BL. Ligand docking and binding site analysis with PyMOL and Autodock/Vina. J Comput-Aided Mol Des. 2010;24:417-422. doi:10.1007/s10822-010-9352-6

24. Hyosu M, Kimura J. Two new spongian diterpenes from Coscinoderma mathewsi. $J$ Nat Prod. 2000;63:422-423. doi:10.1021/np990464e

25. Bokesch HR, Pannell LK, McKee TC, Boyd MR. Coscinamides A, $\mathrm{B}$ and $\mathrm{C}$, three new bis indole alkaloids from the marine sponge Coscinoderma sp. Tetrahedron Lett. 2000;41:6305-6308. doi:10.1016/ S0040-4039(00)01062-5
26. Gonzalez, M A. Scalarane sesterterpenoids. Curr Bioact Compd. 2010;6:178-206. doi:10.2174/157340710793237362

27. Jeong H, Latif A, Kong C-S, et al. Isolation and characterization of antiplasmodial constituents from the marine sponge Coscinoderma sp. Zeitschrift für Naturforschung C. 2019;74:313-318. doi:10.1515/ znc-2019-0039

28. Kimura J, Ishizuka E, Nakao $\mathrm{Y}$, et al. Isolation of 1-methylherbipoline salts of halisulfate-1 and of suvanine as serine protease inhibitors from a marine sponge, coscinoderma $\mathrm{m}$ athewsi. J Nat Prod. 1998;61:248-250. doi:10.1021/np970376z

29. Lee J-W, Lee H-S, Shin J, et al. Suvanine analogs from a Coscinoderma sp. marine sponge and their cytotoxicities against human cancer cell lines. Arch Pharmacal Res. 2015;38:1005-1010. doi:10.1007/s12272-014-0479-1

30. Singh AV, Ansari MHD, Rosenkranz D, et al. Artificial intelligence and machine learning in computational nanotoxicology: unlocking and empowering nanomedicine. Adv Health Mat. 2020;9:1901862. doi:10.1002/adhm.201901862

31. Singh AV, Rosenkranz D, Ansari MHD, et al. Artificial intelligence and machine learning empower advanced biomedical material design to toxicity prediction. Adv. Intellig. Sys. 2020;2:2000084. doi:10.1002/aisy.202000084

32. $\mathrm{Xu} \mathrm{C}$, Lu P, Gamal El-Din TM, et al. Computational design of transmembrane pores. Nature. 2020;585:129-134. doi:10.1038/ s41586-020-2646-5

33. Frankson R, Yu Z-H, Bai Y, et al. Therapeutic targeting of oncogenic tyrosine phosphatases. Cancer Res. 2017;77:5701-5705. doi:10.1158/ 0008-5472.CAN-17-1510

34. Pinch BJ. Identification of a potent and selective covalent Pin 1 inhibitor. Nat Chem Biol. 2020;1-9.

35. Sarver P, Acker M, Bagdanoff JT, et al. 6-Amino-3-methylpyrimidinones as potent, selective, and orally efficacious SHP2 inhibitors. J Med Chem. 2019;62:1793-1802. doi:10.1021/acs.jmedchem.8b01726

36. Zhang D, Iyer LM, He F, Aravind L. Discovery of novel DENN proteins: implications for the evolution of eukaryotic intracellular membrane structures and human disease. Front Genet. 2012;3:283.

37. Sreenivasulu R, Reddy KT, Sujitha P, Kumar CG, Raju RR. Synthesis, antiproliferative and apoptosis induction potential activities of novel bis (indolyl) hydrazide-hydrazone derivatives. Bioorg Med Chem. 2019;27:1043-1055. doi:10.1016/j.bmc.2019.02.002

38. Shaker DS, Shaker MA, Hanafy MS. Cellular uptake, cytotoxicity and in-vivo evaluation of Tamoxifen citrate loaded niosomes. I $J$ Pharmaceutics. 2015;493:285-294. doi:10.1016/j. ijpharm.2015.07.041

39. Paolino D, Cosco D, Muzzalupo R, et al. Innovative bola-surfactant niosomes as topical delivery systems of 5-fluorouracil for the treatment of skin cancer. I $J$ Pharmaceutics. 2008;353:233-242. doi:10.1016/j.ijpharm.2007.11.037

40. Alvi IA. Comparative study of transfersomes, liposomes, and niosomes for topical delivery of 5-fluorouracil to skin cancer cells: preparation, characterization, in-vitro release, and cytotoxicity analysis. Anticancer Drugs. 2011;22:774-782. doi:10.1097/ CAD.0b013e328346c7d6

41. Salatin S, Maleki Dizaj S, Yari Khosroushahi A. Effect of the surface modification, size, and shape on cellular uptake of nanoparticles. Cell Biol Int. 2015;39:881-890. doi:10.1002/cbin.10459

42. Singh AV, et al. Machine-learning-based approach to decode the influence of nanomaterial properties on their interaction with cells. ACS Appl Mater Interfaces. 2020.

43. Singh AV, Jahnke T, Wang S, et al. Anisotropic gold nanostructures: optimization via in silico modeling for hyperthermia. ACS Appl. Nano Mater. 2018;1:6205-6216. doi:10.1021/acsanm.8b01406

44. Hajizadeh MR, Maleki H, Barani M, et al. In vitro cytotoxicity assay of D-limonene niosomes: an efficient nano-carrier for enhancing solubility of plant-extracted agents. Res Pharm Sci. 2019;14:448. doi:10.4103/1735-5362.268206 
45. Tran MA, Watts RJ, Robertson GP. Use of liposomes as drug delivery vehicles for treatment of melanoma. Pigm Cell Melanoma Res. 2009;22:388-399. doi:10.1111/j.1755-148X.2009.00581.x
46. Xu L, Wempe MF, Anchordoquy TJ. The effect of cholesterol domains on PEGylated liposomal gene delivery in vitro. Ther Delivery. 2011;2:451-460. doi:10.4155/tde.11.13

\section{Publish your work in this journal}

The International Journal of Nanomedicine is an international, peerreviewed journal focusing on the application of nanotechnology in diagnostics, therapeutics, and drug delivery systems throughout the biomedical field. This journal is indexed on PubMed Central, MedLine, CAS, SciSearch ${ }^{\mathbb{Q}}$, Current Contents ${ }^{\mathbb{B}} /$ Clinical Medicine, $^{2}$
Journal Citation Reports/Science Edition, EMBase, Scopus and the Elsevier Bibliographic databases. The manuscript management system is completely online and includes a very quick and fair peer-review system, which is all easy to use. Visit http://www.dovepress.com/ testimonials.php to read real quotes from published authors. 